\title{
Isolation and Characterization of Mycoplasmas (PPLO) from Patients with Rheumatoid Arthritis, Systemic Lupus Erythematosus and Reiter's Syndrome
}

\author{
By Lee E. Bartholomew
}

Using tissue culture methods, mycoplasmas (PPLO) were isolated from synovial fluid, bone marrow, kidney, or serum of 14 of 17 patients with either rheumatoid arthritis, systemic lupus erythematosus, or Reiter's syndrome. Sensitivity to various antibiotics and the ability to ferment glucose varied, but all strains were sensitive to tetracycline, and hemolysed sheep cells. Antigenic relationships, studied by complement fixation and growth inhibition, revealed minor differences among the strains, except one which appeared culturally and antigenically distinct. Growth inhibition against several recognized human mycoplasmas was demonstrated.
Con le utilisation de methodos histocultural, mycoplasmas (PPLO-organismos pleuropneumonia-simile) esseva isolate ab liquido synovial, medulla ossee, ren, o sero in 14 de 17 patientes con arthritis rheumatoide, disseminate lupus erythematose, o syndrome de Reiter. Le sensibilitate pro varie antibioticos e le capacitate de fermentar glucosa variava $a b$ un linea al altere, sed omnes esseva sensibile pro tetracyclina, e omnes hemolysava cellulas ovin. Le relationes antigenic, studiate per tests a fixation de complemento e inhibition de crescentia, revelava solmente minor differentias inter le lineas, con le exception de un sol. Isto pareva esser culturalmente e antigenicamente distincte. Esseva demonstrate inhibition de crescentia contra plure recognoscite mycoplasmas human.

T HIS STUDY WAS INITIATED in 1961 as a long-term project of vira] isolation from patients with rheumatoid arthritis (RA), systemic lupus erythematosus (SLE) and Reiter's syndrome. Using tissue culture methods and multiple cell types, including primary and continuous lines, no evidence of cytopathic effect (CPE) suggesting viral infection was observed.

Over 50 specimens were originally studied, consisting mainly of synovial fluid, but also including a few specimens of pleural fluid, bone marrow, and extracts of kidney and spleen. Tissue culture tubes were passaged up to 10 times to uncover low titer agents. Occasionally, increased cell destruction appeared, but this could not be confirmed on subsequent passages. Similar negative reports have appeared in the literature. ${ }^{1-4}$ However, mycoplasmas (pleuropneumonia-like organisms, PPLO) appeared in several cultures previously inoculated with synovial fluid from patients with RA. Because of the frequent occurrence of mycoplasma contamination in continuous cell lines, ${ }^{5-11}$

From the Rackham Arthritis Research Unit and Department of Internal Medicine, University of Michigan Medical School, Ann Arbor, Michigan. The Rackham Arthritis Research Unit is supported by a grant from the Horace H. Rackham School of Graduate Studies. This: study was supported in part by a grant from Parke, Davis and Co., Ann Arbor, Michigan.

Presented in part at the Annual Meeting of the American Rheumatism Association, June 18 and 19, 1965, in San Francisco, California. 
this report describes the results with two cell lines free of these organisms: diploid human embryonic lung fibroblasts and primary African green monkey kidney cells.†

\section{Materials and Methods}

Screw cap glass test tubes were inoculated with $2 \times 10^{5}$ monkey kidney cells and grown in Melnick's "A" medium for 3 or 4 days, at the end of which time there was a confluent monolayer of cells. Medium was changed to Melnick's " $\mathrm{B}$ " maintenance medium, and 4 tubes were inoculated with each specimen. Thereafter, medium was changed at weekly intervals and the $\mathrm{pH}$ adjusted as necessary.

Human embryonic lung fibroblasts were supplied in tubes 24 to 48 hours old, which were originally inoculated with $10^{5}$ cells. Growth medium was Eagle's basal medium 80 per cent and fetal calf serum 15 per cent. After receipt of the cultures, medium was replaced with a maintenance medium of Eagle's basal medium 90 per cent, and fetal calf serum 10 per cent, and 4 tubes were inoculated with each specimen. Medium thereafter was changed weekly, and the $\mathrm{pH}$ was adjusted as necessary. Both cell lines were incubated at $37 \mathrm{C}$. No antibiotics were used in tissue culture media at any time.

At the end of 3 weeks, the culture tubes containing medium and cells were frozen to $-20 \mathrm{C}$., and thawed once. One-tenth milliliter of medium and cells was then passed into new culture tubes which were maintained in a similar manner. At the same time, $0.1 \mathrm{ml}$. of medium and cells was inoculated into PPLO broth. For each rack of 70 culture tubes 8 were controls. Four were passaged and four were non-passaged controls.

Inocula consisted of original or new specimens of synovial fluid, bone marrow, pleural fluid, urine, serum, and extracts of spleen and kidney. These samples were obtained under sterile conditions, except for the spleen and kidney specimens which were obtained at necropsy. If not used immediately, the specimens were kept frozen at $-20 \mathrm{C}$. Synovial fluid and pleural fluid were diluted 1:50 with Eagle's basal medium before inoculation into culture tubes. Serum and urine specimens were diluted 1:10. Kidney and spleen specimens were ground with sterile sand using approximately 10 times the volume of basal medium, and were centrifuged at 800 RPM for 10 minutes. The supernate was then diluted 1:50 and inoculated into culture tubes. The same diluted samples were inoculated directly into PPLO broth and passed at weekly intervals. At every other passage, aliquots of broth were inoculated on PPLO agar.

Cell culture tubes were observed daily at $100 \mathrm{x}$ magnification for evidence of CPE, and PPLO agar petri dishes were examined daily for 10 days under similar magnification for PPLO colonies.

The PPLO broth and agar formulae used were those described by Chanock, ${ }^{12}$ using 7 parts Difco PPLO broth or agar, 1 part yeast extract (Fleischman's 20-40), and 2 parts horse serum (not heat inactivated). No antibiotics or antifungal agents were added. Both broth and agar were incubated at $37 \mathrm{C}$. under 95 per cent nitrogen and 5 per cent carbon dioxide.

Identification of PPLO colonies was made by their morphological appearance, and by their staining reaction with the Diene's stain.13,14 Positive PPLO broth cultures were maintained by passage at 3 or 4 day intervals. Samples were frozen at $-20 \mathrm{C}$. during early passages and intermittently thereafter. They remained viable for 6 months in the frozen state.

The ability of the various isolated strains to ferment glucose was determined by inoculating $0.2 \mathrm{ml}$. of a 48 hour broth culture into $4 \mathrm{ml}$. of PPLO broth containing 1 per cent glucose and 0.005 per cent phenol red. Acid formation was noted by color change. Control tubes showed no $\mathrm{pH}$ change.

Hemolysin production of the strains was determined using an agar overlay method. ${ }^{15}$

${ }^{*}$ Kindly supplied by Dr. R. Brackett, Parke, Davis and Company.

łTrypsinized cell suspension from Flow Laboratory. 
Both guinea pig and sheep red cells were used. A heavy inoculum of organisms was grown on PPLO agar so that confluent growth occurred. At 48 hours the red cell agar overlay was added. Incubation then proceeded aerobically, and evidence of hemolysis was first noted at 48 hours.

Qualitative antibiotic sensitivity was determined using standard bacteriologic sensitivity discs. * PPLO agar petri dishes $(35 \times 10 \mathrm{~mm}$.) were inoculated with 48 hour broth cultures of the various mycoplasma strains. The inoculum was allowed to cover the entire agar surface. After 1 hour, a single antibiotic disc was placed in the center and the plate was incubated anaerobically. Zones of growth inhibition were measured daily, and the final reading taken at 5 days. The following antibiotic concentrations were tested: streptomycin $5 \mu \mathrm{g}$, tetracycline $5 \mu \mathrm{g}$, chloramphenicol $10 \mu \mathrm{g}$, and kanamycin $5 \mu \mathrm{g}$. A number of the strains were tested against penicillin 50 units $/ \mathrm{ml}$. in broth culture, and, as expected, they were resistant.

\section{Production of Rabbit Antisera}

Five of the isolated strains (A-DS, A-MK, H-MGs, A-AJ and H-EM) were used to immunize rabbits. One milliliter of 48 hour broth cultures were inoculated into $50 \mathrm{ml}$. of PPLO broth in a $125 \mathrm{ml}$. flask, orcillating 50 times per minute. The cultures were incubated for 5 days aerobically, with intermittent sampling on PPLO agar to determine growth. Growth curves had shown that maximum growth occurred in 3 or 4 days. The broth cultures were then centrifuged at $17,300 \times \mathrm{g}$ for 30 minutes, the pellet washed once in $0.15 \mathrm{M}$ phosphate buffered saline, $\mathrm{pH} 7.4$ and recentrifuged. The final pellet was suspended in $2.0 \mathrm{ml}$. of buffered saline. New Zealand rabbits were inoculated at weekly intervals with $0.5 \mathrm{ml}$. of antigen combined with $0.5 \mathrm{ml}$. of complete Freund's adjuvant. Each rabbit received 3 injections subcutaneously, and was bled 1 week after the last injection.

\section{Complement-fixation Tests}

Antigens of the same 5 strains were produced in a similar manner as above, except that human serum replaced horse serum to eliminate antigen-antibody reactions due to serum components. The mycoplasma strains were passed at least 4 times in medium containing human serum before growing the complement-fixing antigen. As described by Chanock, ${ }^{16}$ phenol was added to a final concentration of 0.5 per cent at the end of maximum growth ( 5 days). Incubation was then continued for another 2 days. The organisms were then centrifuged and washed as described above, and the final pellet was suspended in $8.0 \mathrm{ml}$. of buffered saline for the stock antigen.

The standard one-fifth volume Kolmer complement-fixation test was used.17,18 Serial dilutions of the stock antigen from 1:2 to $1: 128$ were tested against serial ten-fold dilutions of homologous rabbit antisera and maximum antigen titer determined. The dilution of stock antigen was usually $1: 8$, and was not anticomplementary. Two units of complement were always used. Reading standards were prepared, 18 and a $2+$ reaction or more was considered a positive test. Control tubes without antigen were set up for each dilution in order to be certain the antisera were not anticomplementary.

Cross complement-fixation tests were performed using each of the 5 antigens against each of the 5 rabbit antisera. Pre-immunization rabbit sera were tested against homologous antigen and all revealed negligible antibody titer. A mock antigen of PPLO broth alone was tested against each rabbit antibody, and the titers were 1:20 or below.

\section{Neutralization Tests}

Dilutions of the 5 rabbit antisera were tested for their ability to inhibit growth of the isolated mycoplasma strains. The following final dilutions of antisera were incorporated into PPLO broth: 1:100, 1:500, I:1000, and I:2000. Human serum instead of horse serum

\footnotetext{
*Difco-Bacto-sensitivity disks.
} 
Table 1.-Isolation of Mycoplasma

\begin{tabular}{|c|c|c|}
\hline Patient & Source & Results \\
\hline \multicolumn{3}{|c|}{ Rheumatoid Arthritis } \\
\hline E. M. & Syn. fluid & + HEL $\nmid$ \\
\hline L. H. & Syn. fluid & + HEL \\
\hline M. G. $(8 / 29)$ & Syn. fluid & + HEL \\
\hline M. G. $(8 / 29)$ & Serum & + HEL \\
\hline M.G. $(9 / 10)$ & Syn. fluid & + HEL \\
\hline H. H. & Syn. fluid & 0 \\
\hline C. F. & Pleural fluid & ) \\
\hline M. K. & Syn. fluid & + AGMK \\
\hline W. H. & Syn, fluid & $+\mathrm{AGMK}, \mathrm{HEL}$ \\
\hline \multicolumn{3}{|c|}{ Systemic Lupus Erythematosus } \\
\hline D. B. & Kidney & + AGMK \\
\hline D. M. & Kidney* & + AGMK \\
\hline A. $\mathbf{J}$. & Marrow & $+\mathrm{AGMK}$ \\
\hline G. B. & Kidney & 0 \\
\hline H. N. & Syn. fluid & $+\mathrm{AGMK}$ \\
\hline V. LC, & Urine & 0 \\
\hline \multicolumn{3}{|c|}{ Reiter's Syndrome } \\
\hline O. D. & Syn. fluid & 0 \\
\hline J. H. & Syn. Huid & + AGMK \\
\hline D. F. & Syn. fluid & + HEL \\
\hline D.S. & Syn. fluid & + AGMK \\
\hline
\end{tabular}

"Necropsy specimens.

†HEL = Human embryonic lung fibroblasts.

$\$$ AGMK $=$ African green monkey kidney cells.

was used in the PPLO broth to eliminate possible horse serum antibody precipitation reactions. The tubes containing rabbit antisera and the controls were inoculated with dilutions of the 14 isolated mycoplasma strains, using 1:100 normal pooled rabbit sera for controls. After 24 and 48 hours incubation, aliquots were plated on PPLO agar (not containing antisera). Colony counts were made at 1,2 , and 4 days, and inhibition of growth was determined as compared to the controls containing the same lot of human serum with 1:100 normal rabbit serum. Fifty per cent or more decrease in colony count was considered significant. The human sera used in the neutralization tests were checked for inhibitory properties against all the mycoplasma strains by comparing their growth in PPLO medium containing horse serum.

Earlier attempts to study growth inhibition by incorporating the antisera in agar and inoculating directly as described by Edward and Fitzgerald ${ }^{19}$ were less sensitive. Results were identical when the antisera were heat inactivated at $56 \mathrm{C}$. for 30 minutes, indicating that complement was not necessary for growth inhibition. A similar finding was described by Edward and Fitzgerald. ${ }^{19}$

Four human mycoplasma strains (M. hominis I, M. hominis II, M. salivarium, and M. fermentans) were compared with the isolated strains.

\section{Results}

A total of 14 mycoplasma strains were isolated from 17 patients with either RA, SLE, or Reiter's syndrome. They were isolated from cell culture after

${ }^{*}$ Kindly supplied by Dr. D. G. Edward. 
Table 2.-Isolation of Mycoplasma

\begin{tabular}{llll}
\hline & \multicolumn{1}{c}{ Souree } & \multicolumn{1}{c}{ Diagnosis } & Results \\
\hline Patient & \multicolumn{1}{c}{ Other Conditions } & \\
G. A. & Syn. Hluid & Traumatic arthritis & 0 \\
F. L. & Syn. Hluid & Traumatic arthritis & 0 \\
C. O. & Syn. fluid & Osteoarthritis & 0 \\
J. C. & Syn. fluid & Osteoarthritis & 0 \\
H. S. & Syn. Huid & Gout & 0 \\
F. K. & Syn. Hluid & Chronic leukemia & 0 \\
W. M. & Spleen & Polyarteritis & 0 \\
\hline
\end{tabular}

*Necropsy specimen.

2 to 6 passages. CPE was not apparent despite multiple passages with known mycoplasma present. Occasionally increased granularity and cell degeneration were noted at the bottom of the tube. Increased acidity in the inoculated tubes was noted on two or three occasions.

Tables 1 and 2 show the number of isolations attempted, the source of the material, diagnosis and cell lines which were positive. Several times mycoplasma were isolated more than once from the same specimen. Mycoplasma were isolated from three different specimens from patient M. G. Both synovial fluid and serum obtained 8/29/63 were positive. Eleven days later the synovial fluid was also positive.

None of the specimens shown in table 2 was positive. They were inoculated and passed concurrently with the others and served as disease controls.

In general, the human embryonic lung fibroblasts were more satisfactory for isolating mycoplasma from patients with RA, while monkey kidney cells were superior in patients with SLE. Early passages of the organisms in PPLO medium showed only a moderate number of colonies, but on repeated passages, they grew abundantly, with slight turbidity appearing in the medium.

Figure 1 shows the appearance of the colonies on PPLO agar. All but one strain showed the typical fried egg appearance. Strain A-DS always developed a lacy network unlike the others. When compared to four human strains (fig. 2), only minor morphological differences with the other strains were noted. All of the isolated strains stained with the Dienes method.

None of the isolates grew at room temperature or in PPLO medium when the serum component was omitted. After they were established, all grew well aerobically.

Table 3 shows the results of antibiotic sensitivity, glucose fermentation, and sheep cell hemolysis of 13 of the isolated strains, and four human strains. As a group, the strains were resistant to streptomycin, and quite sensitive to tetracycline. Sensitivity to kanamycin and chloramphenicol varied considerably. Strains A-DM and A-DF were similar to $M$. fermentans in antibiotic sensitivity. The others showed differences from the human strains.

The ability of the strains to ferment glucose varied considerably. Two strains (A-DS and A-DM) were non-fermenters. Four strains (A-DF, H-MG, 

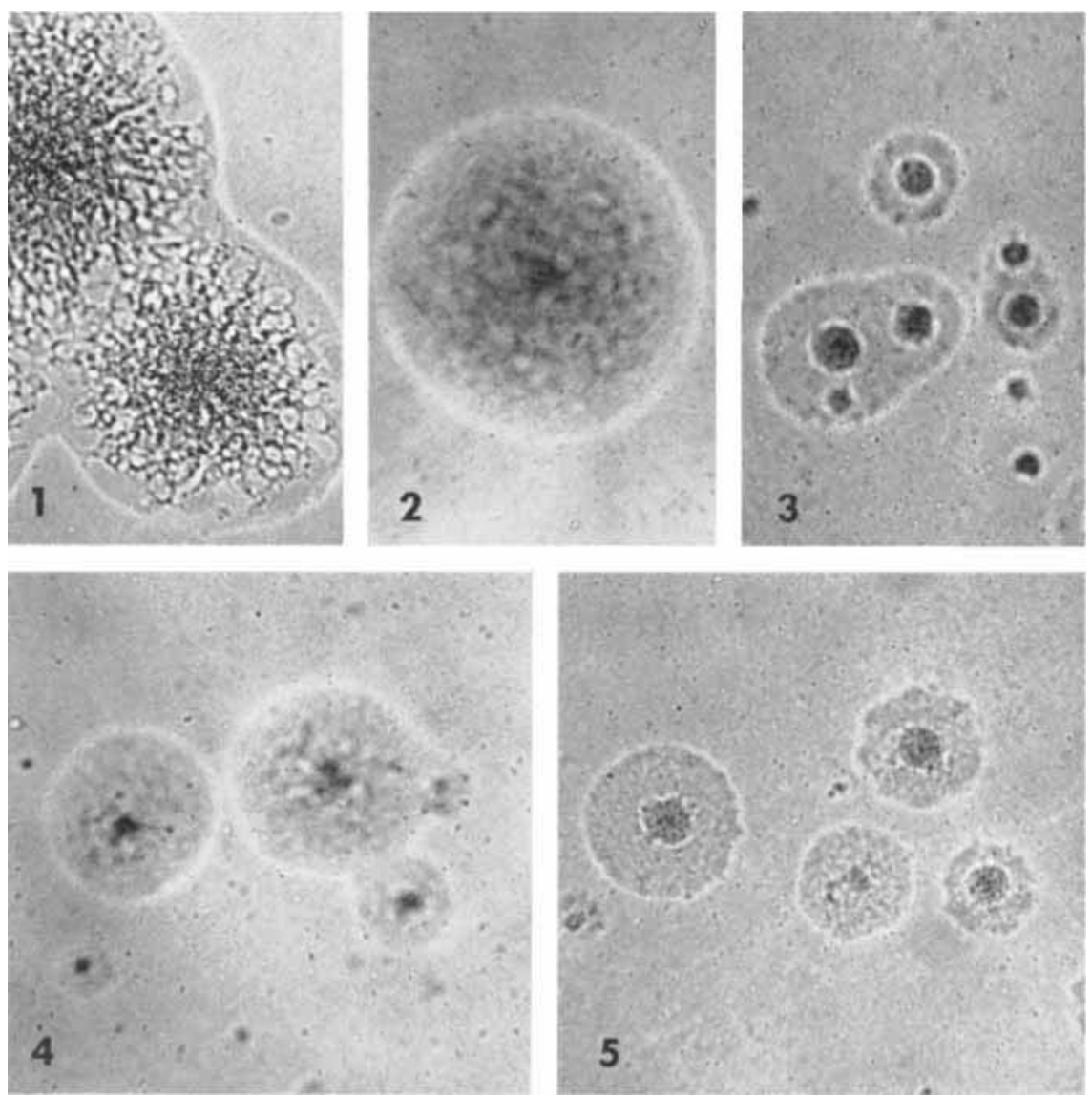

Fig. 1.-Photomicrographs of isolated myocplasma colonies on PPLO agar. The colonies are unstained, and the original magnification is approximately $100 \mathrm{x}$. (1) A-DS from synovial fluid of Reiter's syndrome; (2) A-MK from synovial fluid of RA; (3) H-MGs from serum of RA; (4) H-EM from synovial fluid of RA; and (5) A-AJ from bone marrow of SLE.

H-MGs and H-EM) were quite active and of the same degree as $\mathbf{M}$ fermentans. The others showed only slight fermentation after 3 or 4 days.

All of the strains except one (A-DS) hemolysed sheep red cells actively. This was not a true beta hemolysis, but an alpha or incomplete hemolysis. However, a definite ring of hemolysis occurred around the confluent growth of colonies. A-DS showed only slight hemolysis over the colonies as did M. hom. I. The other 3 human strains tested did not hemolyse sheep cells. Hemolysis with guinea pig cells was much less distinct.

Table 4 shows the results of the cross complement-fixation tests with rabbit antibody against 5 strains. While there was evidence of common antigenicity among the five strains, A-DS appeared distinct from the others.

The results of the neutralization tests are shown in table 5. Each of the 13 isolated strains was tested against rabbit antisera to strains A-DS, A-MK, H-MGs, H-EM and A-AJ. Similarly, four human mycoplasmas, (M. hom I, M, 

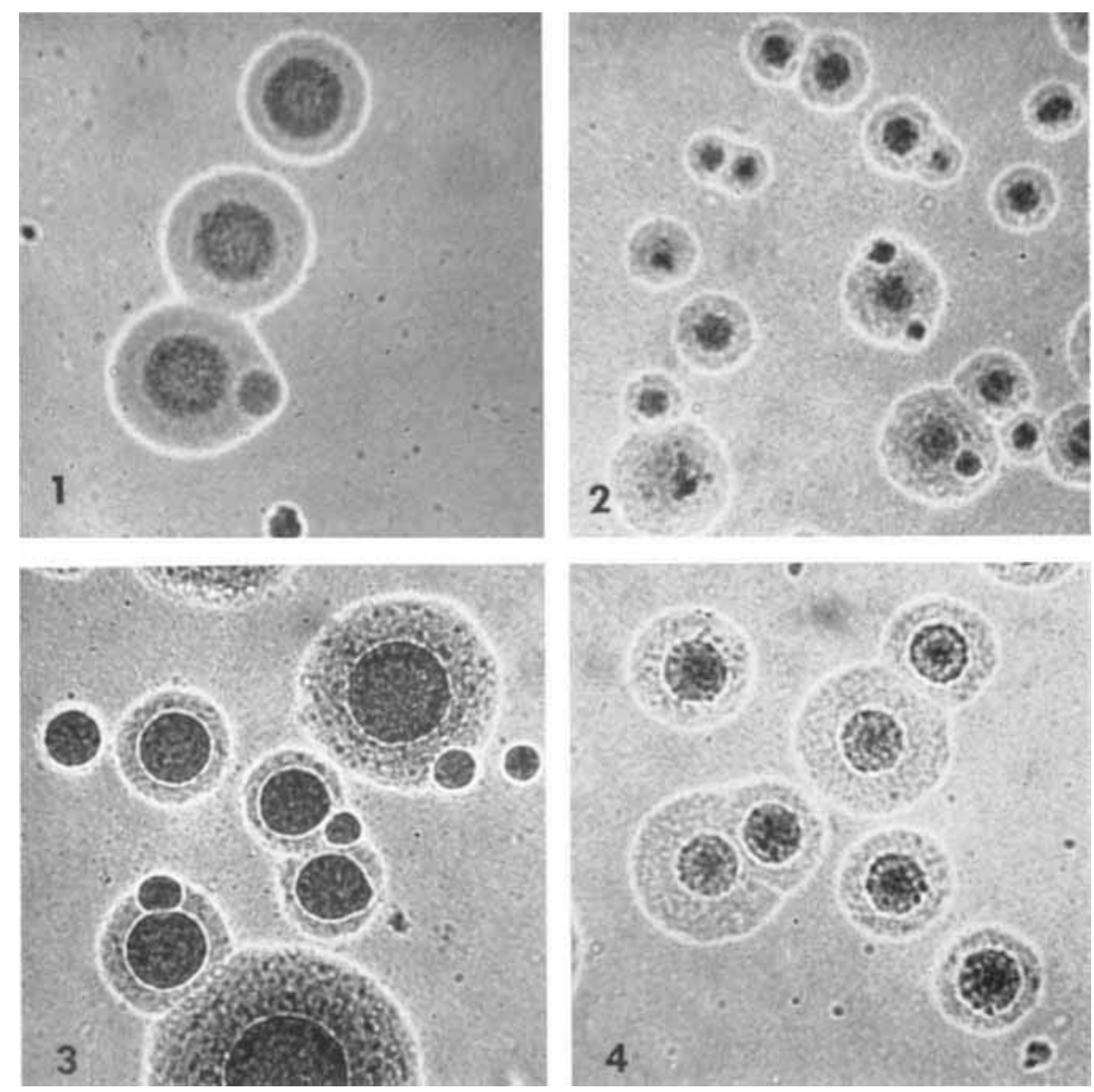

Fig. 2.-Photomicrographs of 4 known human mycoplasma strains growing on PPLO agar. The colonies are unstained, and the original magnification is approximately 100x. (1) M. hominis I, H 50; (2) M. hominis II "Campo"; (3) M. salivarium, H 110; and (4) M. fermentans " $G$ " strain.

hom. II, M. sal. and M. fer.), were tested against the 5 rabbit antisera. Again A-DS appeared distinct from the other 12 strains which appeared to be closely related.

The neutralization patterns of the 5 rabbit antisera against the four known human strains are of interest. In each case, the pattern was different, indicating an antigenic relationship to one or more of the 4 human strains. When growth inhibition occurred, the end-point was definite, with 90 to 100 per cent decrease in colony count.

\section{Discussion}

Using tissue culture methods, mycoplasmas were isolated from 14 of 17 patients with several connective tissue diseases. Passaged control cultures and specimens from patients with the other conditions shown in table 2 were negative. Isolation of organisms by direct inoculation into PPLO medium was unsuccessful despite multiple passages. 
Table 3.-Mycoplasma Characteristics

\begin{tabular}{|c|c|c|c|c|c|c|}
\hline \multirow[b]{2}{*}{ Strain } & \multicolumn{4}{|c|}{ Antibiotic Dise Sensitivity } & \multirow[b]{2}{*}{$\begin{array}{c}\text { Glucose } \\
\text { Fermentation }\end{array}$} & \multirow[b]{2}{*}{$\begin{array}{l}\text { Sheep RBC } \\
\text { Hemolysis }\end{array}$} \\
\hline & $\begin{array}{l}\text { Strep. } \\
5 \mu \mathrm{g} .\end{array}$ & $\begin{array}{l}\text { Tetra. } \\
5 \mu \mathrm{g} .\end{array}$ & $\begin{array}{l}\text { Chlor. } \\
10 \mu \mathrm{g} .\end{array}$ & $\begin{array}{l}\text { Kan. } \\
\mathbf{5} \mu \mathrm{g} .\end{array}$ & & \\
\hline \multicolumn{7}{|l|}{ Reiter's } \\
\hline A-DS & $\mathrm{R}$ & $10 \mathrm{~mm}$. & $\mathrm{R}$ & $3 \mathrm{~mm}$. & 0 & Sl \\
\hline$A-D F$ & $\mathrm{R}$ & $S^{*}$ & $S$ & $9 \mathrm{~mm}$. & + & + \\
\hline$A-J H$ & $2 \mathrm{~mm}$ & $\mathrm{~S}$ & $7 \mathrm{~mm}$ & $4 \mathrm{~mm}$ & Sl & + \\
\hline \multicolumn{7}{|l|}{$R A$} \\
\hline H-MGs $†$ & $\mathbf{R}$ & $\mathrm{S}$ & $11 \mathrm{~mm}$. & $9 \mathrm{~mm}$ & + & + \\
\hline 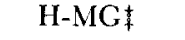 & $\mathbf{R}$ & $\mathrm{S}$ & $12 \mathrm{~mm}$ & $12 \mathrm{~mm}$ & + & + \\
\hline A-MK & $\mathrm{R}$ & $S$ & $5 \mathrm{~mm}$ & $5 \mathrm{~mm}$ & Sl & + \\
\hline H-WH & $\mathbf{R}$ & $\mathrm{S}$ & $7 \mathrm{~mm}$. & $5 \mathrm{~mm}$. & Sl & + \\
\hline H-EM & $1 \mathrm{~mm}$. & $S$ & $8 \mathrm{~mm}$ & $5 \mathrm{~mm}$ & + & + \\
\hline H-LH & $\mathbf{R}$ & $S$ & $9 \mathrm{~mm}$ & $8 \mathrm{~mm}$. & Sl & + \\
\hline \multicolumn{7}{|l|}{ SLE } \\
\hline $\mathrm{A}-\mathrm{AJ}$ & $\mathrm{R}$ & $S$ & $13 \mathrm{~mm}$ & $10 \mathrm{~mm}$ & Sl & + \\
\hline$A-D B$ & $\mathrm{R}$ & $\mathrm{S}$ & $8 \mathrm{~mm}$. & $6 \mathrm{~mm}$. & SI & + \\
\hline$A-D M$ & $\mathrm{R}$ & $\mathrm{S}$ & $\mathrm{S}$ & $6 \mathrm{~mm}$. & 0 & + \\
\hline $\mathrm{A}-\mathrm{HN}$ & $\mathrm{R}$ & $\mathrm{S}$ & $8 \mathrm{~mm}$ & $7 \mathrm{~mm}$ & Sl & + \\
\hline \multicolumn{7}{|l|}{ Iuman Type } \\
\hline m. hom. I & $\mathrm{R}$ & $S$ & $\mathbf{R}$ & $S$ & 0 & Sl \\
\hline m. hom. II & $\mathrm{R}$ & $7 \mathrm{~mm}$ & $5 \mathrm{~mm}$ & $3 \mathrm{~mm}$ & 0 & 0 \\
\hline m. sal. & $\mathrm{R}$ & $4 \mathrm{~mm}$. & $\mathbf{R}$ & $4 \mathrm{~mm}$ & 0 & $\mathbf{0}$ \\
\hline m. fer. & $\mathrm{R}$ & $S$ & $S$ & $7 \mathrm{~mm}$ & + & 0 \\
\hline
\end{tabular}

$\mathrm{R}=$ Resistant.

${ }^{\circ} \mathrm{S}=$ Sensitive, $15 \mathrm{~mm}$. or more.

† Isolated from serum.

\$Isolated from synovial fluid 11 days later.

$\mathrm{Sl}=$ Slight.

Table 4.-Complement Fixation Tests

\begin{tabular}{|c|c|c|c|c|c|}
\hline \multirow[b]{2}{*}{ PPLO Antigen } & \multicolumn{5}{|c|}{ Rabbit Antiserum to Mycoplasma Strains } \\
\hline & A-DS & A-MK & H-MGs & A-AJ & H-EM \\
\hline A-DS & $1280^{*}$ & 160 & 80 & 160 & 160 \\
\hline $\mathrm{A}-\mathrm{MK}$ & 320 & 5120 & 640 & 2560 & 2560 \\
\hline H-MGs & 320 & 1280 & 1280 & 1280 & 1280 \\
\hline $\mathrm{A}-\mathrm{A} J$ & 320 & 1280 & 320 & 1280 & 640 \\
\hline H-EM & 160 & 1280 & 2560 & 640 & 2560 \\
\hline
\end{tabular}

*Reciprocal of dilution.

Several possibilities are apparent. The mycoplasmas could be contaminants from cell cultures, from components of the media, or by direct contamination. Mycoplasmas could be present in the original tissue but unrelated to the disease process. Or, the organisms could be directly related to the disease.

The problems of tissue culture contamination by mycoplasma are well known. While continuous cell lines are often contaminated, there is little evidence that primary cell lines are.$^{5,11,20}$ For this reason, two primary cell lines were chosen from different sources, each line using entirely different 
Table 5.-Antigenic Relationships of Isolated Mycoplasmas to Each Other and to Four Recognized Human Strains by Growth Inhibition

\begin{tabular}{cccccc}
\hline & \multicolumn{5}{c}{$\begin{array}{c}\text { Final Dilutions of Rabbit Antisera Causing 50\% or } \\
\text { More Decrease in Colony Count }\end{array}$} \\
\cline { 2 - 5 } Strain & *A-DS & A-MK & †H-MGs & A-AJ & H-EM \\
\hline Reiter's & $1: 2000$ & 0 & 0 & 0 & $1: 100$ \\
A-DS & $1: 100$ & $1: 2000$ & $1: 2000$ & $1: 2000$ & $1: 1000$ \\
A-DF & $1: 100$ & $1: 2000$ & $1: 2000$ & $1: 1000$ & $1: 1000$ \\
A-JH & & & & & \\
RA & 0 & $1: 2000$ & $1: 2000$ & $1: 2000$ & 0 \\
H-MGs & 0 & $1: 2000$ & $1: 2000$ & $1: 2000$ & $1: 2000$ \\
H-MG & $1: 100$ & $1: 2000$ & $1: 2000$ & $1: 1000$ & $1: 2000$ \\
A-MK & 0 & $1: 500$ & $1: 100$ & $1: 2000$ & 0 \\
H-WH & 0 & $1: 2000$ & $1: 2000$ & $1: 2000$ & $1: 1000$ \\
H-EM & 0 & $1: 2000$ & $1: 2000$ & $1: 2000$ & $1: 2000$ \\
H-LH & & & & & \\
SLE & 0 & $1: 2000$ & $1: 2000$ & $1: 1000$ & $1: 2000$ \\
A-AJ & $1: 100$ & $1: 2000$ & $1: 2000$ & $1: 1000$ & $1: 2000$ \\
A-DB & 0 & $1: 2000$ & $1: 2000$ & $1: 2000$ & $1: 2000$ \\
A-DM & $1: 100$ & $1: 2000$ & $1: 2000$ & $1: 2000$ & $1: 2000$ \\
A-HN & & & & & \\
Human Types & $1: 2000$ & $1: 2000$ & $1: 2000$ & 0 & $1: 500$ \\
M. hom. I & 0 & $1: 100$ & $1: 100$ & $1: 1000$ & $\mathbf{0}$ \\
M. hom. II & $1: 1000$ & $1: 100$ & $1: 100$ & 0 & $1: 2000$ \\
M. sal. & 0 & $1: 1000$ & 0 & $1: 2000$ & $1: 2000$ \\
M. fer. & 0 & & & &
\end{tabular}

*A = Isolated from African green monkey kidney cells.

$\dagger \mathrm{H}=$ Isolated from human embryonic lung cells.

$\ddagger 0=$ No growth inhibition at 1:100 dilution or greater.

$\S$ Strain isolated from serum.

\|Isolated from synovial fluid 11 days later.

media. All of the control cells remained negative. There was no correlation between the cell line of isolation and its characteristics. Thus, there were no common features in the mycoplasmas isolated using monkey kidney cells, which were not present in the strains isolated using embryonic lung cells.

If the isolated strains were similar as to their cultural, biologic, antibiotic and antigenic patterns, this would lend support to a common contaminant theory. However, their ability to ferment glucose and antibiotic sensitivity varied, with no correlation between antibiotic sensitivity and fermentation activity. The common biologic patterns were their ability to hemolyse sheep cells, their requirement for enriched medium and their inability to grow at room temperature.

Antigenic relationships among 5 of the strains studied by complementfixation tests revealed considerable cross reactivity. A-DS appeared distinct from the other four which appeared identical. Eleven of the 13 isolates were neutralized by antisera to strains A-MK, H-MGs, A-AJ, and H-EM. Strain $\mathrm{H}-\mathrm{WH}$ appeared more closely related to A-AJ than to the other 4 strains, and A-DS appeared distinct. 
Neutralization tests with the 4 human strains showed that the patterns in each were different, and that in each case except one (antiserum H-MGs), significant growth inhibition occurred with two or three of the human strains (table 5). As these strains were not cloned, a mixture is possible.

Indirect evidence would not favor this explanation. Thus antiserum H-MGs does not neutralize M. fer., but H-MGs organisms ferment glucose activity. Yet antiserum H-MGs neutralizes strains H-EM, A-MK, and A-AJ which show antigenic similarity to $\mathrm{M}$. fer. Likewise, the 90 to 100 per cent growth inhibition in almost every case would not favor a mixture of antigenically different organisms. Morphologically, all colonies observed of strain A-DS appeared identical throughout 45 passages. Yet antiserum to A-DS inhibited both $\mathrm{M}$. hom. I and M. sal.

None of the isolates can as yet be positively identified, but they appeared to be related to characterized human strains. Other strains have to be considered. None resembled M. pneumoniae either by its small mulberry colony form, or by its beta hemolysis. M. orale ${ }^{21}$ and M. pharyngis, ${ }^{22}$ are non-fermenters. Isolates A-DS and A-DM could be related to these. M. laidlawii strains are saphrophytic and ferment glucose. However, they will grow at room temperature and in serum-free medium ${ }^{23}$ unlike the isolated strains.

It would appear that these strains represent a group of organisms fairly closely related to each other with minor cultural and antigenic differences. No great differences were noted in the strains isolated from patients with different clinical diseases.

There is no evidence that the strains are " $\mathrm{L}$ " forms. Inducers, such as penicillin, were not used at any stage. Multiple broth passages (up to 45) have not shown reversion to bacteria. Antigenic relationships to known human mycoplasmas would be unlikely if they were "L" forms.

The concept that some of the rheumatic diseases are caused by micro-organisms is not new, and mycoplasmas have often been considered. Particular attention has been given to Reiter's syndrome as possibly caused by mycoplasma. There is suggestive evidence of venereal transmission in this disease. ${ }^{24-26}$ While mycoplasmas have been isolated from the urethral discharge of these patients, ${ }^{4,26-28}$ rarely have they been isolated from synovial fluid of affected joints. ${ }^{26.29-35}$ Johnson $^{34}$ has reported isolation of "mycoplasma-like" organisms from synovial fluid of several cases of polyarthritis which he considered as possible atypical RA, but none was isolated from definite RA. He found similar organisms in psoriatic arthropathy and ankylosing spondylitis. However, he was unable to subculture these strains. These reported studies have described direct isolation procedures inoculating specimens directly into PPLO medium. Ford, ${ }^{36}$ however, was unable to isolate mycoplasmas from patients with Reiter's syndrome, using a cell culture method somewhat similar to that used in this study.

If these mycoplasma strains did arise from the original specimens, one must assume they are extremely fastidious; they may require a period of adaption, within or in proximity to living cells, before they can grow in cell-free medium. The relative ease of isolating mycoplasma from the genito-urinary tract and 
oropharynx by direct culture, and the very rare instances in which they have been cultured from body tissues may reflect this problem.

\section{Patient Characteristics}

\section{Rheumatoid Arthritis}

Of the 5 patients from whom mycoplasma were isolated, one (L. H.) had juvenile arthritis for 6 years; the other four were adults. Two (E. M. and W. H.) were latex positive. M. G. has had episodic RA for 3 years. The disease duration of the others was 3 to 12 years. Rheumatoid nodules were present in two (W. H. and E. M.). The disease was active in all patients.

Drug therapy varied considerably: one (L. H.) received only aspirin, two (M. K. and W. H.) had had gold therapy in the past, and one (E. M.) was receiving gold at the time of isolation. M. G. had received steroids in the past.

\section{Systemic Lupus Erythematosus}

Two of the 4 patients from whom mycoplasma were isolated were adults (D. B. and H. N.) aged 37 and 48 years. Two (A. J. and D. M.) were children aged 13 and 15 years. All four had typical multisystem involvement and had positive LE tests. Disease duration was 1 to 4 years.

All four were receiving steroids at the time the specimens were obtained, and one (H. N.) was also taking hydroxychloroquine.

Complete autopsies were performed on two patients (D. M. and D. B.), at which time the tissues for inoculation were obtained. In both cases the typical pathologic features of SLE were present, including lupus nephritis, lamellar fibrosis of the splenic arteries, and hematoxylin bcdies.

\section{Reiter's syndrome}

The age range of the 3 male patients from whom mycoplasma were isolated was 26 to 42 years. Each had associated conjunctivitis and non-specific urethral discharge with their arthritis. The synovial fluid specimens were obtained 2 to 4 weeks after the onset of arthritis. At that time these patients were taking no drugs other than aspirin.

One patient $(\mathrm{J} . \mathrm{H}$.) developed an acute severe form of psoriasis approximately 6 months after the original Reiter's attack.

\section{ACKNOWLEDGMENTS}

The author appreciates the excellent technical assistance of Mrs. Joan Himes who has participated in this study since its inception. The advice and encouragement of Dr. E. F. Payne, Department of Virology, The University of Michigan School of Public Health, likewise are deeply appreciated.

\section{REFERENCES}

1. Ford, D. K.: Further tissue culture studies of non-gonococcal urethritis and Reiter's syndrome. Brit. J. vener. Dis. $34: 53,1958$.

2. Utz, J. P., Phelps, E. T., and Smith, L. G.: Rheumatoid arthritis: Viral studies of adult human synovial Huid and tissue using tissue culture techniques. Bull. Georgetown Univ. Med. Center 12:198, 1959.

3. Clarke, S. K. R.: Attempt to isolate a virus from biopsy material in cases of 
rheumatoid arthritis. Ann. Rheumat. Dis. 17:51, 1958.

4. Csonka, G. W., and Furness, G.: A study of the aetiology of non-gonococcal urethritis and Reiter's disease. Brit. J. vener. Dis. 36:181, 1960.

5. Rothblat, G. H.: PPLO contamination in tissue cultures. Ann. N. Y. Acad. Sci. 79:430, 1960.

6. Coriell, L. L., Fabrizio, D. P., and Wilson, S. R.: Comparison of PPLO strains from tissue culture by complement fixation. Ann. N. Y. Acad. Sci. $79: 574,1960$.

7. Robinson, L. B., Wichelhausen, R. H., and Roizman, B.: Contamination of human cell cultures by pleuropneumonia-like organisms. Science 124: 1147, 1956.

8. Collier, L. H.: Contamination of stock linss of human carcinoma cells by pleuropneumonia-like organisms. Nature 180:757, 1957.

9. Pollock, M. E., Kenny, G. E., Syverton, J. H.: Isolation and elimination of pleuropncumonia-like organisms from mammalian cell cultures. Proc. Soc. Exp. Biol. and Med. 105:10, 1960.

10. Bailey, J. S., Clark, H. W., Felts, W. R., Fowler, R. C., and Mc P. Brown, $\mathrm{T}$ : Antigenic properties of pleuropneumonia-like organisms from tissue cultures and the human genital area. J. Bacteriol, 82:542, 1961.

11. Herderschee, D., Ruys, C., and van Rhijn, G. R.: Pleuropneumonia-like organisms in tissue culture. Antonie van Leeuwenhoek 29:368, 1963.

12. Taylor-Robinson, D., Somerson, N. L., Turner, H. C., and Chanock, R. M.: Serological relationships among human mycoplasmas as shown by complement-fixation and gel diffusion. J. Bacteriol. 85:1261, 1963.

13. Dienes, L.: L organism of Klieneberger and Streptobacillus moniliformis. J. Inf. Dis. 65:24, 1939.

14. Madoff, S.: Isolation and identification of PPLO, Ann. N. Y. Acad. Sci. 79:383, 1960.

15. Clyde, W. A., Jr.: Hemolysis in identifying Eaton's pleuropneumonia-like organism. Sci. 139:55, 1963.

16. Chanock, R. M., James, W. D., Fox, H. H., Turner, H, C., Mufson, M. A., and Hayflick, L.: Growth of Eaton PPLO in broth and preparation of complement fixing antigen. Proc. Soc. Exp. Biol. and Med. 110:884.

17. Kolmer, J. A.: The technique of the Kolmer complement fixation tests for syphilis employing one-fifth amounts of reagents. Am. J. Clin. Path. 12: $109,1942$.

18. Laboratory Procedures for Modern Syphilis Serology. U. S. Dept. Health, Education and Welfare 1962, p. 2740.

19. Edward, D. G. ff., and Fitzgerald, W. A.: Inhibition of growth of pleuropneumonia-like organisms by antibody. J. Path. and Bacteriol. 68:23, 1954.

20. Carski, T. R., and Shepard, C. C.: Pleuropneumonia-like (Mycoplasma) infections of tissue culture. J. Bacteriol. 81:626, 1961.

21. Taylor-Robinson, D., Canchola, J., Fox, H., and Chanock, R. M.: A newly identified oral mycoplasma ( $\mathrm{M}$. orale) and its relationship to other human mycoplasmas. Am. J. Hyg. 80: 135, 1964.

22. Clyde, W. A., Jr.: Mycoplasma species identification based on growth inhibition by specific antisera. J. Immunol. 92:958, 1964.

23. E. A. Freundt: The Mycoplasmataceae. Munksgaard, Copenhagen, 1958, p. 54.

24. Ford, D. K.: Natural history of arthritis following venereal urethritis. Ann. Rheumat. Dis. 12:177, 1953.

25. Harkness, A. H.: Non-gonococcal urethritis, Livingstone, Ltd. Edinburgh, Scotland, 1950, p. 99.

26. Kuzell, W. C., and Mankle, E. A.: Cultivation of pleuropneumonia-like organisms in Reiter's disease, including one instance of laboratory cross infection. Ann. N. Y. Acad. Sci. 79: $650,1960$.

27. Klieneberger-Nobel, E.: Pleuropneumonia-like organisms in genital infections. Brit. Med. J. 1:19, 1959.

28. Oates, J. K., Whittington, M. J., and Wilkinson, A. E.: A note on the results of cultural and serological tests for pleuropneumonia-like organisms in Reiter's disease. Brit. J, vener. Dis. 
35:184, 1959.

29. Dienes, L., Ropes, M. W., Smith, W. E., Madoff, S., and Bauer, W.: The role of pleuropneumonia-like organisms in genito-urinary and joint diseases. New Engl. J. Med. Vol. 238, Part I, p. 509 and Part II, p. 563, 1948.

30. Varthin, T. A.: Reiter's syndrome. Am. J. Med. 4:827, 1948.

31. Kuzell, W. C., and Mankle, E. A.: Cortisone acetate and terramycin in polyarthritis of rats. Proc. Soc. Exp. Biol. and Med. 74:677, 1950.

32. Butas, C. A.: The isolation of pleuropneumonia-like organisms from two cases of polyarthritis. Canad. J. Mi- crobiol. 3:419, 1957.

33. Schaffarzick, R. W., and Mankle, E. A.: Reiter's disease and pleuropneumonia-like organisms. Stanford Med. Bull. 11:262, 1953.

34. Jonsson, J.: Mycoplasma organisms in synovial fluid from rheumatic joints. Acta Rheum. Scand. 7:287, 1961.

35. Dienes, L., and Smith, W. E.: Studies of the incidence and pathogenicity of pleuropneumonia-like organisms in humans. J. Clin. Invest. 25:911, 1946.

36. Ford, D. K.: The relationship of human genital pleuropneumonia-like organisms to arthritis complicating urethritis. Arth. \& Rheumat. 3:395, 1960.

Lee E. Bartholomew, M.D., Assistant Professor Internal Medicine, Department of Internal Medicine, The University of Michigan Medical School; Associate Physician, Rackham Arthritis Research Unit, The University of Michigan, Ann Arbor, Mich. 